Sheffield Centre for

Hallam

Regional Economic

University and Social Research

\title{
An evaluation of Prioritise Me
}

\section{Beth Speake and Jan Gilbertson}

\section{August 2020}

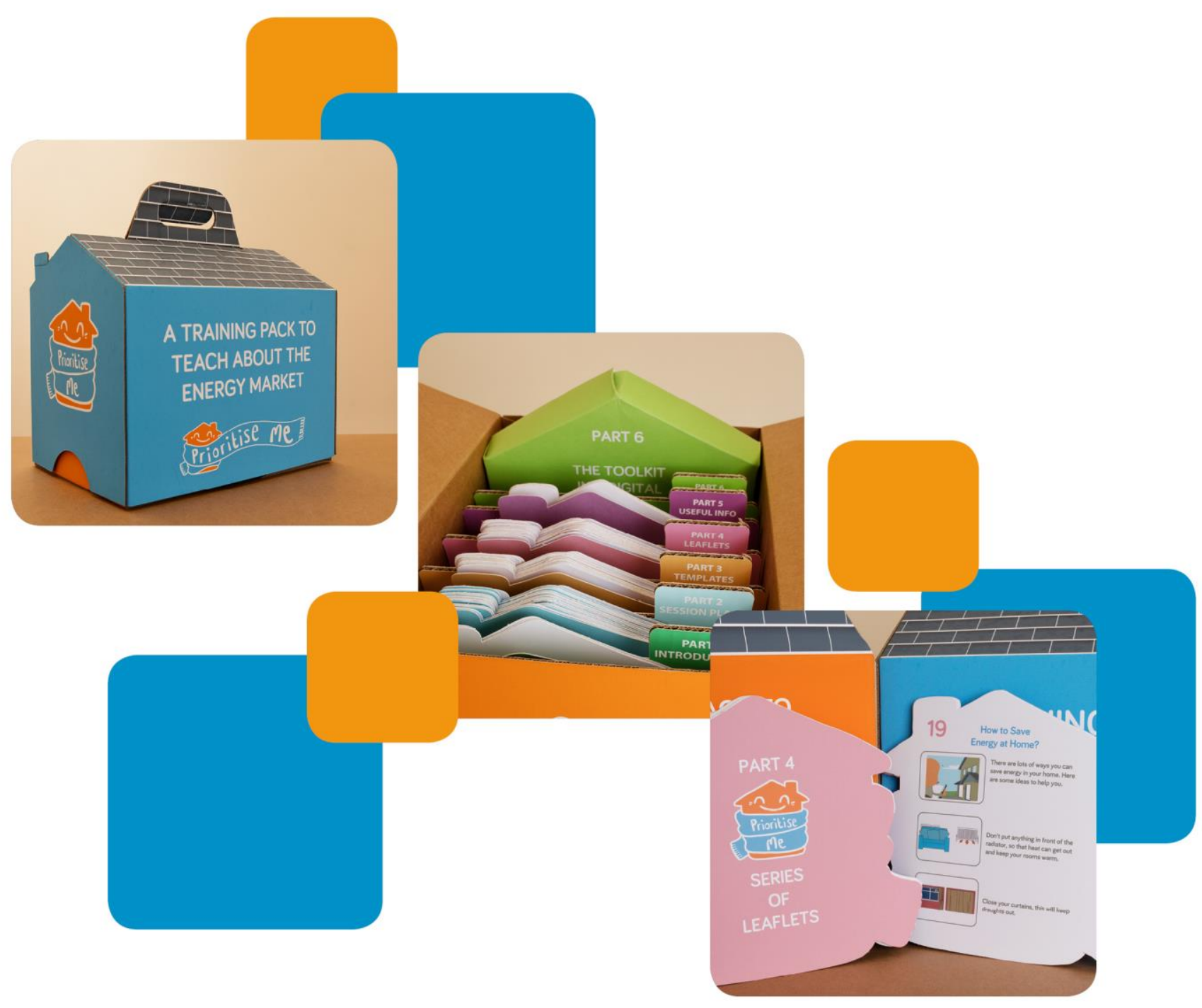




\section{An evaluation of Prioritise Me}

\section{Authors:}

Beth Speake

Jan Gilbertson

Date: August 2020

DOI: 10.7190/cresr.2020.3985880565 


\section{Acknowledgements}

We are grateful to all the workers and self-advocates at Speakup who supported the evaluation. We would particularly like to thank all the individuals and organisations who contributed to interviews, testimonials, and case studies. 


\section{Contents}

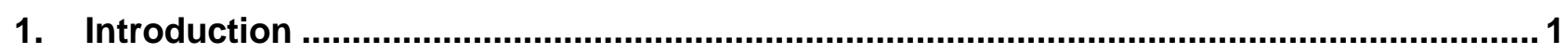

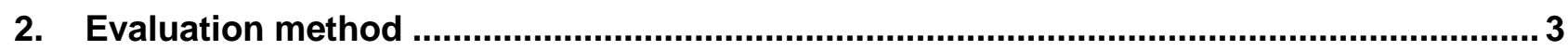

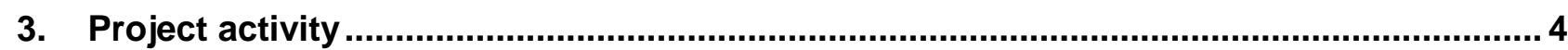

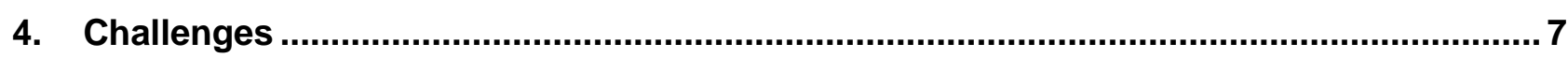

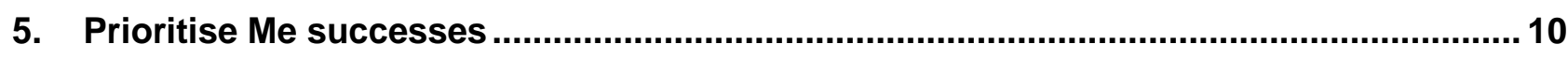

6. Conclusions, learning and next steps................................................................... 15 


\section{Introduction}

This short report presents the findings from an evaluation of the Prioritise Me training programme. The evaluation was carried out between February 2019 and August 2020 by the Centre for Regional Economic and Social Research (CRESR) at Sheffield Hallam University. The evaluation team at CRESR worked closely with Speakup to develop the evaluation. Speakup also worked with researchers and designers at the University of Sheffield and Sheffield Hallam University to coproduce and develop training materials and resources for the programme.

\subsection{Background and development}

The Prioritise Me project is being led by Speakup Self Advocacy Limited, a registered charity which is run by and for people with learning disabilities and autistic people. Speakup gives people with learning disabilities and autistic people a voice, employment opportunities, and makes sure that they are valued and included in society. The Prioritise Me training programme (also known as 'Prioritise Me') was developed from an earlier project called Being Warm - Being Happy (BWBH), which was a study of fuel poverty experienced by adults with a learning disability (AWLD) in England.

The BWBH project explored the extent to which AWLD are put at a disadvantage by the existing energy market. Towards the end of $\mathrm{BWBH}$ a colleague from National Energy Action mentioned the Priority Services Register (PSR), a service through which energy suppliers provide extra help to vulnerable energy consumers. BWBH generated a range of recommendations including raising awareness of the energy companies' PSR and was the source for the development of initial ideas for applications to the Energy Redress Fund, one of which was the Prioritise Me project. Prior to BWBH, Speakup was involved in a project called I'm An Expert Energy Saver, funded by the Scottish Power Energy People Trust. As part of this project, two short films were made which are still on the Speakup website and continue to be used as additional resources for the Prioritise Me training.

\subsection{Objectives and intended outcomes}

The aim of the Prioritise Me project was to support vulnerable people who are energy consumers in genuinely creative ways, and to support capacity and understanding for people with learning disabilities and/or autism. Prioritise Me aimed to provide accessible and interactive advice and training about energy use and the energy market where understanding was limited; to develop accessible ideas and resources through piloting innovative work with University design and evaluation partners; and to engage people to speak confidently to energy providers, giving maximum impact for vulnerable adults in South Yorkshire. 
The PSR for vulnerable consumers gives extra help and support with energy supply issues including things like: free advice on being more energy efficient; annual gas safety checks; protection from cold callers; free of charge meter move if it is difficult for someone to access and/or read it, as well as other support. This free service is overseen by Ofgem and provided by energy suppliers and network operators. Each energy supplier and network operator maintains their own register. To get on it, consumers need to contact their energy supplier. Many vulnerable consumers do not know about the PSR and often lack the confidence to contact their energy supplier, so a main purpose of the Prioritise Me training is to provide the necessary support to increase awareness of the PSR and signpost people to this service.

The intended outcomes of the Prioritise Me training were as follows:

- A minimum of $\mathbf{5 0 0}$ people with increased awareness of the PSR and have been signposted to this.

- A dynamic training package designed and developed in co-production with people with learning disabilities and/or autism, with a minimum of $\mathbf{2 5 0}$ people with learning disabilities and/or autism having attended a training session or workshop delivered by our champions with learning disabilities.

- 5 partner organisations involved in the testing, training and workshops delivered by our people with lived experience.

- 200 organisations in South Yorkshire contacted and given access to the training package online, with a nationwide launch through the Speakup website and partner organisations towards the end of the project.

- Collaborative working achieved across the partnership with regard to developing accessible resources, enabling capacity building and confidence for people significantly less able to protect and represent themselves in the energy market.

The Prioritise Me project involved a team of people from Speakup, researchers and designers from Sheffield Hallam University and the University of Sheffield. Original Prioritise Me partner organisations included Keyring, ChAD, Socialeyes, RAP, and Barnsley Voices. Disability Sheffield became a partner organisation during the project. 


\section{Evaluation method}

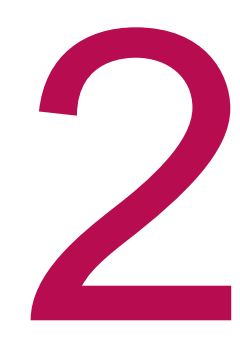

The evaluation of the Prioritise Me training programme is a small-scale qualitative evaluation and is based on the following activity:

- $\quad$ Project steering group meetings.

- 1 initial meeting with self-advocates and workers at Speakup.

- 1 observation of a training session.

- 1 interview with the Speakup manager.

- 3 telephone/video-conferencing interview case studies with beneficiaries and trainers.

- 6 written case studies from beneficiaries.

- 3 telephone interviews with stakeholders from Prioritise Me collaborative partners.

The evaluation was designed to: gather information on the development and implementation of the Prioritise Me training programme; document and assess its progress and challenges; and examine programme benefits and impacts.

Initially, it was intended that 8 case study interviews with beneficiaries would be conducted in their homes or at a supporting organisation's premises. COVID-19 and the imposition of lockdown measures meant that it was necessary to be flexible around research methods, however, and it was decided that case study interviews with beneficiaries would be conducted over the phone or via video-conferencing software, according to the preferences of the participant, where possible. Other case studies were provided as written testimony from participants, where necessary aided by their supporting organisation.

The project and evaluation were carried out over 18 months from February 2019 to August 2020. 


\section{Project activity}

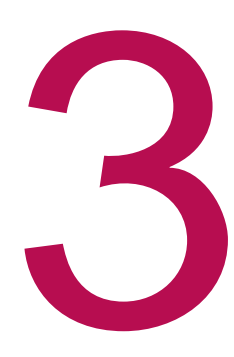

The original project programme as outlined in the funding bid was largely adhered to. Minor revisions were made as a result of personnel changes and other changes due to COVID-19, as indicated in the quarterly monitoring and grant claim forms submitted by Speakup to the Energy Redress Scheme.

Specific elements of the programme to be highlighted are as follows.

\subsection{Development of training}

The training was initially developed through two workshops run which took place with AWLD at Speakup in March and April of 2019. A key element of this work was the importance attached to the role and contribution of self-advocates. The first workshop generated initial personas by drawing pictures of what they might look like, and then thinking about a set of training topics for each persona which they would want to know more about. These topics were then organised and clustered around the following themes: technology; getting a better energy deal; the PSR and how to support customers; making your house more efficient; and problems with energy bills. The second workshop developed the personas in more detail and produced a summary of challenges for each persona. Following this, the training was developed with self-advocates at Speakup, with 9 different groups who attend across the week involved in informal training development sessions.

A key feature of how the Prioritise Me training was developed was that the ideas incorporated into the training resources through these initial workshops came from the self-advocates' experiences as AWLD. Speaking about the benefits of coproduction, an employee and self-advocate at Speakup responsible for delivering training commented:

"the best thing to do is ask the person with learning disabilities or autism what is best for them, because they will be able to tell you themselves".

\subsection{Development of resources}

With the consent of The University of Sheffield, the "house" box design was created by design researcher Remi Bec, who created the content and graphic based on the original design of the house from the BWBH project. Through the initial workshops and extensive trialling and testing, the training pack was created in collaboration between Remi and the Speakup team. As one Speakup worker explained:

"before we went to the different groups to talk to them, we tried it [the "house" training pack] out with Speakup groups first to test it to see if any changes need to be done on it, if people could understand it, about the different tariffs, the different presentations that we did with the groups." 
The "house" box contains cards with written information, also shaped like houses, of different colours according to the relevant sections; an Easyread workbook with illustrations to print, which covers the entire training programme; and a CD-ROM which contains all the training materials developed by Speakup, including the Easyread Guides to tariffs; switching; smart meters; keeping your house warm; a presentation about how to get on the PSR; and the Energy Quiz. In addition, the Speakup team have made three short films covering important topics for the Prioritise Me training: The PSR; Tariffs and Switching; and Reading Your Meter.

All of these resources are now available on the Speakup website at https://www.Speakup.org.uk/prioritiseme

\subsection{Delivery of training and information dissemination}

Prioritise Me met or exceeded all its delivery of training and information dissemination programme objectives set out in the original funding bid:

- $\quad$ Prior to the lockdown which resulted from the COVID-19 pandemic, 10 Prioritise $\mathrm{Me}$ training sessions had been delivered to collaborative partners by the Speakup team.

- 301 people have attended training sessions either with partner organisations or at Speakup (target 250).

- Over $\mathbf{5 0 0}$ organisational networks have been made aware of the PSR, and large national organisations including NHS England and Learning Disability England have pledged to publicise the PSR (target 200).

- An estimated 227 people had been reached at community events attended by Speakup before the start of lockdown.

- Keyring delivered some of the training individually to members they were supporting, pledging to make sure that people knew about the PSR and were signed up where possible with help from support workers.

- Disability Sheffield have delivered one face-to-face training session, and three online sessions via Zoom, and intend to continue to deliver this training.

- $\quad$ ChAD have delivered three face-to-face training sessions to SMILE (Supportive Multi-Ability Inter-Generational Life Experiences) services in South Yorkshire.

- The online launch of the Prioritise Me training resources was completed in August 2020, and around 150 emails were sent to organisations nationwide to highlight these resources and ensure a lasting legacy for the project.

Concerted networking efforts by the Speakup team around the Prioritise Me project has also extended the reach of the training and ensured that the information is being disseminated even more widely than anticipated. For example, Disability Sheffield, who were not an original collaborative partner, have been very involved and have delivered several training sessions themselves, as indicated above, and they continue to publicise the training to their partners in Sheffield. Before lockdown, they delivered one face-to-face Prioritise Me training session at Heeley City farm in Sheffield. Approximately 16 people attended this session, with a mixture of people living in supported accommodation and people living independently. The training was delivered as a facilitated group discussion, following the form of delivery modelled by the Speakup team in the initial training session. As a worker from Disability Sheffield commented:

"We didn't know at the time that we were going to be involved in delivering the training, but it [training session delivered by Speakup] was great, they're 
amazing, and it gave us an idea of what it was about, and the delivery style as well [...] a facilitated group discussion, rather than - stand up and talk in front of somebody."

When the imposition of lockdown meant that no further training sessions could be delivered face-to-face, workers at Disability Sheffield used the online Prioritise Me resources to deliver further training around Prioritise Me via regular Zoom meetings attended by $10-15$ people:

"I can easily share my screen with the Zoom meeting people, so that's going really well, we just do it in really small chunks because the Zoom meetings arepeople want to have fun - so it's a bit of information, a bit of fun, a bit of information, a bit of fun, so it's just slowly, slowly, trickling down, like - have you thought about what switching your energy company looks like?" 


\section{Challenges}

Several challenges were identified during the evaluation.

\subsection{Process}

One of the main challenges relates to the process of delivering the training. Our main finding is that for the Prioritise Me training to be successful for the whole audience, flexibility is essential. Trainers may need to take additional steps to aid the engagement of participants with differing capabilities in the training. In most groups, worker and trainer to trainee ratio is likely to be an issue, therefore there is a need to be clear on group numbers and worker availability in advance. In bigger groups in particular, some advance planning and pairing of trainees into mixed ability pairs where possible would be ideal, so that where workers/trainers can't support, they can work together and engage with the training on some level: As one trainer commented "people need different levels of support to understand it". Overall, feedback from self-advocates and trainers suggests that the Prioritise Me training programme is most useful for those with a level of independent living.

Other challenges were also highlighted:

- As outlined in their Quarter 3 monitoring and grant claim form, colleagues at Speakup acknowledged that, as expected, the training cohort was very mixed ability, and that extensive trialling and testing had been necessary in the development of the training. Speakup responded to this challenge by trying to develop very flexible training resources which would allow all participants to benefit in some way and take some learning from the training sessions.

- Capacity issues continue to present a challenge both for Speakup and for partner organisations. The impact of COVID-19 exacerbated issues of limited capacity due to the furlough of workers at some partner organisations.

- Digital exclusion presents a barrier for some AWLD, and this is ever more crucial for those who are vulnerable or shielding during the COVID-19 pandemic.

- $\quad$ There has been a disappointing response from some large organisations to mail outs regarding the PSR.

- Organisations are not allowed to sign people up to the PSR; rather they can only signpost service users to the register. Workers at Speakup predicted that they could have had 300 to 400 people signed up if they had been able to provide immediate support to service users to sign up.

- One colleague at Speakup received numerous nuisance calls from energy companies after signing up for the PSR, which led to her changing her mobile phone number. However, it would appear that this issue has not been reported more widely. 
- It was originally envisaged that participants would come to training sessions with some basic information about their energy use, for example their provider contract or a gas and electricity bill. However, as detailed below, it was decided that this part of the session was too complex and Speakup adapted this section of the training to focus on auto-switching services.

\subsection{Resources/materials}

The main challenge related to the materials produced for the project is that the "house" training pack requires a relatively high level of reading ability, which means it is not suitable for a lot of self-advocates to use by themselves. Some trainers also needed support to use those information cards in the house which are particularly dense with information. For this reason, it is more suited to being used more as a resource for trainers than trainees.

The following challenges were also highlighted:

- The section of training about understanding energy bills required modification. Initially, two colleagues at Speakup printed their energy bills to bring to the training session and do a comparison. However, as one worker commented, "you'd have needed to be a mathematician to work out what was going on". There are many people in the training cohort who are not in charge of paying for their gas and electric; others often have a personal assistant who might help them to understand their bills and how to save money or switch. Furthermore, the trainers noted that at this point in the training session, participants began to "glaze over". For this reason, rather than focusing on specific information about the rates being charged, this section has been adapted to focus on promoting auto-switching services.

- Due to ERF funding rules about not benefiting or showing favouritism for any particular energy company, Speakup have been unable to use energy company logos in any of their training materials. Speakup responded to this challenge by designing an energy bill, ID card and envelope with Speakup portrayed as an energy company, to use as an example. However, workers at Speakup identified this as problematic because it was potentially confusing for participants.

- Change is fast paced in the energy market, with companies, terminology, and technology often being updated. This means that information in the training pack can become out of date fairly quickly.

- One stakeholder reported a "level of disappointment" with the "house" training pack, stating that it was too dense with information and replicated the information in the workbook. They felt that the house would have been more useful if it was full of activities or miniature models of household items relating to energy which could be used by all trainees.

- In a training session delivered to one of the collaborative partners, the Speakup team noted that more visuals and items were needed to aid understanding, for example larger laminated colour pictures of a smart meter display and a thermostat; a piece of insulation; and examples of things to keep yourself warm in the house. Due to lockdown this was only implemented with one training group.

\subsection{Impact of COVID- 19}

As a result of the COVID-19 pandemic, several training sessions that were scheduled to take place had to be postponed or cancelled. For example, sessions 
lined up by Speakup with Sheffield MENCAP were not able to go ahead as planned; Speakup were unable to organise a session with RAP for parents and carers; two sessions which ChAD had arranged with SMILE services were postponed; and three training sessions planned by Disability Sheffield were also postponed. In addition, the lockdown has significantly reduced the capacity of partner organisations to engage with the training project. As one stakeholder from a partner organisation commented,

"I think [Prioritise Me] would have been an initiative that we could have really got our teeth into, but it was just the timing really, it just got started up then everyone disappeared [due to the lockdown], so this is something that we hope to bring back into the service when we're back up and running, inform people and put it out there."

The impact of the COVID- 19 pandemic, while significant, has however been somewhat mitigated by the excellent digital resources produced by Speakup for the Prioritise Me training package. As noted above, three short films are available on the website, along with several Easyread guides and a presentation. Speakup noted increased traffic to their website during lockdown. Speakup and collaborative partners have also demonstrated great flexibility by switching to using videoconferencing software to deliver training sessions in different formats and to wider audiences during the lockdown and beyond. 


\section{Prioritise Me successes}

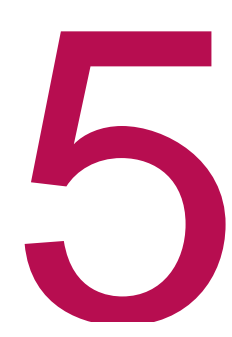

\subsection{Process}

Many successes and impacts have been gained through the process of designing, refining and delivering the Prioritise Me training, and disseminating related information and materials to partners and stakeholders on a local, regional and national level.

Key successes relating to the process identified during the evaluation include:

- $\quad$ Success of co-production process with self-advocates.

- $\quad$ Success of training delivery by self-advocates.

- Excellent networking and development of strong new partnerships.

- $\quad$ Significant strengthening of existing links with partners.

- Extremely successful dissemination.

- Sustainability of the project, in particular via the legacy of both physical and online materials.

- Dissemination of best practice in training.

- Very successful risk management: anticipated risks were managed well by the Speakup team, and the unanticipated risk and challenges posed by COVID-19 were responded to with agility as detailed above, mitigating the impact of COVID-19 on the project.

\subsection{Resources/materials}

The materials produced by the Prioritise Me training programme can be considered a major success, as is evidenced by the case studies and testimonies of selfadvocates and stakeholders. Moreover, collaborative partners emphasised how the online resources had enabled them to continue delivering training around Prioritise Me during lockdown and in the wake of new social distancing guidelines, and to adapt the materials to suit the target groups. One collaborative partner expressed an interest in buying an additional 8 "house" training boxes for use with their national networks, and Speakup have been in conversation with the design researcher Remi $\mathrm{Bec}$, creator of the house pack, to discuss production costs and a potential timeline for this work to be completed.

The main successes can be summarised as follows:

- The "House" training pack is very well designed. A self-advocate from one of the project's collaborative partners commented: 
"I thought the house box was a brilliant useful design with lots of useful information. I liked how it was an accessible way to get the information out to people."

- Genuine co-production with self-advocates ensured that the training covers topics that are important in an accessible way.

- The online materials, including the short films and the Easyread guides, have been highly praised by stakeholders.

- $\quad$ Three short films have been completed and are accessible on the website.

- $\quad$ The Energy Quiz was universally praised by users, although the development of two versions of different lengths might ensure greater benefit for all trainees.

\subsection{Benefits to participants}

Three main benefits of the Prioritise Me training for self-advocates and carers were identified by those who took part in the evaluation:

1. Being registered on the PSR was associated with increased peace of mind.

2. Participants' improved knowledge around why, how and when to switch energy companies to get a better deal.

3. Participants' better understanding of how to heat their homes efficiently.

Increased peace of mind after registering on the PSR was highlighted by several people involved in the evaluation case studies, with S's foster carer stating that it "gives reassurance to a busy household" (Case study 3); while D's mother also said that she found it very useful and that it gave her peace of mind, particularly around possible power cuts (Case study 4). Meanwhile, the importance of improved knowledge around switching should not be underestimated. As one stakeholder emphasised, "historically, people with learning disabilities have things done to them". The Prioritise Me training is empowering AWLD to take control and make informed decisions on the energy issues which affect their everyday lives. As one selfadvocate and trainer from Speakup commented, "I'm more in control now. It's really good learning different skills".

These points are further demonstrated in the following case study:

\section{Case study 5: E and D from Disability Sheffield}

$E$ is 36 and moving into her own flat and preparing for this with her support worker. We ran a private session through Zoom with her and her boyfriend who she is planning to marry and live with in the future. $E$ was really anxious about understanding how her bills worked and whether she would have enough money to cover everything. She didn't know what energy companies where or how to switch to save money [...] D and $\mathrm{E}$ did the quiz with us and we talked about the [PSR], and as soon as $E$ moves she is going to get some help from her support worker to contact the energy company to get signed up.

A better understanding of how to heat homes efficiently and keep the house warm in winter is an important benefit for participants, including those who are not in control of their own energy supply. A and $M$ both live in flats with district heating, where the heating is generated through a centralised location. M explained: 
"I don't know if I am paying too much for my energy because it's all lumped together and I pay an amount of money to a company, but I think this is my housing provider, not an energy company."

Although $\mathrm{A}$ and $\mathrm{M}$ have not been able to control their energy bills, they both said they found the Prioritise Me training useful. This was because part of the training looked at how to be energy efficient and also keep their homes warm and they have used the tips they learned to do this through the winter.

Other benefits for participants were also mentioned by interviewees. Some of these reflected the social value of participating in the project, and the increased confidence and knowledge of self-advocates. As one self-advocate from a partner organisation commented:

"I also enjoyed learning some useful tips on how I can keep my energy bills down and having some useful discussions in the group."

\section{Case study 1: R}

$\mathrm{R}$ lives alone in a one bedroomed bungalow and receives very little support from his family. He is partially sighted and has mild learning disabilities. He has a personal assistant (PA) who joins him for a few hours a week to support his independence. He pays his energy bills by direct debit and finds this the easiest way to manage them. Keeping on top of his bills is a priority during the time that he spends with his PA, but lots of other things such as doctor and hospital appointments often get in the way.

Prior to attending the Prioritise Me training, he did not know about the PSR, so he was interested in the training about how to register. After the training, he asked his PA if she could support him to sign up to the PSR. They said that they found this process easy to do with his energy company and $\mathrm{R}$ commented:

"I now know that my energy company is there to support me if my power goes off."

This means he feels more relaxed about things because of living on his own. $R$ also said he would look at switching energy companies if his PA thought that he was paying too much, because he had been with the same energy company for years.

In the end, R benefitted because he did both these things; he worked together with his PA to switch energy companies, saving money by comparing energy prices, and registering on the PSR of his new company. $R$ switched in the summer, we thought this was a good time so that he did not have lots to pay to his old energy provider to bring his bills up to date during the switch. $R$ was reassured because he had more peace of mind being on the PSR, and he saved money as well.

His PA also said that by supporting $\mathrm{R}$ with his energy bills, this would benefit the other people that she worked with, because it had raised her awareness of the energy market. She went on to say that she would now check that the other people she supported were on the PSR and support them if they were not, to register. She also said that she would check current energy deals with them, to see that they were not paying too much. 


\subsection{Additionality}

The pioneering nature of the Prioritise Me project was largely confirmed by the enthusiasm with which the training and materials were received by the users, especially by those supporting particularly vulnerable and marginalised adults with learning disabilities, and by the very real effect that registering on the PSR has had on peace of mind both for self-advocates and for carers. It is unfortunate that - due to the COVID-19 lockdown - it has not yet been feasible to pursue to a greater extent the possibility of the ideas generated being taken forward by the energy companies themselves.

\subsection{Innovation}

The Prioritise Me project has delivered the intended levels of innovation both in terms of co-production, and in the development of new ideas. There is also the potential for further innovation as the lessons learned from the project are applied both to future revisions of the materials and how the materials can be used, and as new collaborating partners 'run with' adaptations suited to their specific target group needs. Moreover, changes in approaches already initiated in response to the need to adapt to the 'new reality' resulting from COVID-19 have the potential to lead to further innovations.

\subsection{Dissemination and scope for replication}

One of the greatest successes of Prioritise Me has been in terms of dissemination and scope for replication of the approach developed by the project. Specific dissemination of which we are aware includes:

- $\quad 513$ different organisational networks, groups and residential homes signposted to the PSR, considerably exceeding the target of $\mathbf{2 0 0 .}$

- Individual emails sent by Speakup regarding the online resources were sent to many organisations and we know that, following on from this, 253 organisations or their networks have shared this information widely.

- Learning Disability England sent info about the PSR to all their member organisations.

- $\quad$ Shared Lives Rotherham included the Prioritise Me training in their newsletter which is distributed to $\mathbf{4 0}$ carers.

- The Speakup website has been busy since emails about the resources were sent out to their target groups, and large organisations, including NHS England, have shared the resources.

However, the consensus among those interviewed is that the information has got out even more widely and that resources have been picked up by many organisations and individuals. There were also many references to how the materials were useful not just for the intended target group but for their carers', supporters and for workers. 'Word of mouth' dissemination too, should not be underestimated, as people share information with friends and family, and on social media. One self-advocate from a partner organisation explained:

"I have shared what I have learnt with many of my friends who have learning disabilities and autism. I have shared the information at meetings and also with my work team at NHS England. I also shared the priority services register information with my elderly Grandma." 


\subsection{Impact}

It is too early to evaluate the overall impact of the project but it is clear that the project has succeeded in increasing awareness and knowledge about the PSR and the energy market more generally, signposting numerous different organisations, groups and residential homes to the PSR.

Given the already existing outputs and outcomes, the scope for replication of the approach, and the, to-date, excellent dissemination of the results, it is clear that Prioritise Me has the potential to have a significant impact on the understanding of energy services of people with learning disabilities and/or autism, and of other vulnerable and marginalised groups. Further steps needed to maximise this impact are discussed in the next section of the report. 


\section{Conclusions, learning and next steps}

The evaluation of Prioritise Me indicates that the rationale and initial concept for the project, as described in the funding bid, has been validated: the importance and effectiveness of co-production of materials and training in this context has proved itself, and the materials produced have been both innovative and useful. Further, it has been demonstrated that the materials produced by the project have the potential for much wider application, not only for vulnerable groups but for a much wider section of the public, and not only locally but also at a regional level and nationally. Although action in this matter has been limited to some extent by the extra demands on project workers as a result of Covid-19, Speakup has the necessary networks to enable this to happen.

Although the project faced several difficulties, most of the issues were speedily resolved or mitigated, and two issues in particular became important 'learning points', as follows:

- From the feedback it is clear that some of the training materials might have benefitted from greater differentiation to provide a flexible learning experience for a wider range of abilities.

- In the absence of increased capacity or a higher worker to trainee ratio, greater flexibility and some forward planning mitigates a lot of potential problems.

These two key issues, combined with several smaller points, illustrate the desirability of enabling some further revision and development of the 'house' training pack, particularly in terms of maximising the benefit of it as an online tool to be exploited in the future as organisations adapt to the Covid 19 'new normal' situation. Moreover, as noted above in Section 4, fast paced change in the energy market means that some training materials risk going out of date. However, Speakup have already partially responded to this challenge both through the provision of online resources which can be more easily updated, and with the suggestion that if they were to make further "house" training packs they could produce a new CD for inclusion. In addition, as originally envisaged, the revised materials would have the potential to move to 'proof of concept' prior to national manufacture.

\subsection{Next steps}

With regard to the project's next steps, over the final quarter of Prioritise $\mathrm{Me}$ it is anticipated that it will become clearer as to whether there is capacity from organisations to use these resources as a training tool, or if the project will need additional support to complete further face-to-face training, following a resolution to the COVID-19 pandemic. When coronavirus is over, Speakup will revisit the training 
and ensure that anyone wanting face to face training within South Yorkshire will be given the opportunity to attend some update sessions which they will run periodically. 


\section{Sheffield Hallam University}

An evaluation of Prioritise Me

SPEAKE, Beth and GILBERTSON, Janet <http://orcid.org/0000-0003-3338-7590>

Available from the Sheffield Hallam University Research Archive (SHURA) at:

http://shura.shu.ac.uk/27294/

\section{Copyright and re-use policy}

Please visit http://shura.shu.ac.uk/27294/ and http://shura.shu.ac.uk/information.html for further details about copyright and re-use permissions. 